\title{
Application of Genetic Engineering in Plant Breeding for Biotic Stress Resistance
}

\author{
Desalegn Alemayehu \\ Post graduate student at Jimma University College of Agriculture Department of Horticulture and Plant \\ Sciences, Jimma, Ethiopia
}

*Corresponding Author: Desalegn Alemayehu, Post graduate student at Jimma University College of Agriculture Department of Horticulture and Plant Sciences, Jimma, Ethiopia

\begin{abstract}
Genetic engineering has been utilized to improve the function of various metabolic and functional processes within an organism of interest. Its principle is to express non-native genes within the host organism, leading to the expression of previously unavailable protein products. The objective of this paper is to review and discuss the application of genetic engineering in plant breeding for biotic stress resistance. The review was made on application of genetic engineering in plant breeding for biotic stress resistance such as disease, insect and weeds. Through the use of genetic engineering it is possible to develop resistant variety for biotic factors such as disease (bacteria, fungi and virus) insect pest and invasive weeds for any crop plants were reviewed and cited in this paper.
\end{abstract}

\section{INTRODUCTION}

Genetic engineering has been identified as one key approach to increasing agricultural production and reducing losses due to biotic and abiotic stresses in the field and in storage (Yuan et al., 2011). Genetic engineering can be utilized to improve the function of various metabolic and functional processes within an organism of interest. The principles of genetic engineering can be utilized to express non-native genes within the host organism, leading to the expression of previously unavailable protein products (Close et al., 2012). The genetic engineering approach to cross protection was first demonstrated by Powell-Abel and co-workers who expressed the TMV coat protein gene in transgenic plants and obtained some degree of resistance against TMV (Powell-Abel et al., 1986). Controlled expression studies of target genes are used to determine the function of the genes.

In plant biotechnology, over expression of heterologous genes by transgenic methods is widely used to improve industrially important crop plants (Tanaka et al. 2012). Biotechnology, through genetic engineering, has the potential to contribute to increased agricultural production by making crops better able to cope with both biotic and abiotic stress. However this paper primarily deals with resistance to biotic stress. Many transgenic plants resistant to diseases have been produced (Mundembe et al., 2012). In its modern conception, biotechnology is the use of genetic engineering techniques to manipulate microorganisms, plants, and animals in order to produce commercial products and processes that benefit man (Ascacio-Martínez, and Barrera-Saldana ,2012).

The breeding of promising individuals over generations in order to create desirable phenotypic characteristics in plants and animals has long been practiced in horticulture and animal husbandry (Small, 2012). The improvement of crop plants by alteration of traits using traditional plant breeding programme is time consuming and labour intensive. Since last two decades the researchers are switching towards biotechnological approaches for crop improvement. The manipulations in gene expression for quality traits in crop can now easily be achieved by RNAi. It can be employed by identifying the target gene(s) developing vectors as an RNAi construct, transforming plant and finally screening and evaluating the traits (Saurabh et al., 2014). As new technologies are developed, new problems are created. Such is the field of transgenic plants harboring resistance genes, which on the one hand alleviate past difficulties, but on the other leave us with new challenges to face in the future. The objective of this paper is to review and discuss the application of genetic engineering in plant breeding for biotic stress resistance. 


\section{DISEASE RESISTANT CROPS THROUGH GENETIC ENGINEERING}

\subsection{Disease Resistance}

Plant breeding can be a sustainable and effective approach to obtain disease resistance. However, the classical plant-breeding methods are in general slow, laborious and time consuming. Targeted genome editing is a promising alternative to classical breeding (Abbasi et al., 2015). Great progress has been made in the past 25 years in our understanding of the molecular basis of plant disease resistance mechanisms, and of how pathogens circumvent them. These insights can inform more sophisticated approaches to elevating disease resistance in crops that help us tip the evolutionary balance in favour of the crop and away from the pathogen. Wild relatives of domesticated crop species harbor multiple, diverse, disease resistance $(\mathrm{R})$ genes that could be used to engineer sustainable disease control (Steuernagel et al., 2016). However, breeding $\mathrm{R}$ genes into crop lines often requires long breeding timelines of 5-15 years to break linkage between $R$ genes and deleterious alleles (linkage drag). If several cloned $\mathrm{R}$ genes were available, it would be possible to pyramid R genes (Dangl et al., 2013). MutRenSeq can be applied to other commercially relevant crops and their relatives, including, for example, pea, bean, barley, oat, rye, rice and maize (Steuernagel et al., 2016).

Plant diseases can devastate crop yields and pose a threat to global food security. R genes offer an economical and environmentally responsible solution to control plant disease, and cloning of these genes would enable durable $\mathrm{R}$ gene deployment strategies (Steuernagel et al., 2016). Most $\mathrm{R}$ genes encode proteins with nucleotide binding and leucine- rich repeats (NLRs) (Dangl, et al. 2013). R gene enrichment sequencing (RenSeq) of specific gene class involves capturing fragments from a genomic or cDNA library using biotinylated RNA oligonucleotides designed to be complementary to the NLRencoding genes of a reference genome (Jupe et al., 2013; Andolfo et al., 2014). RenSeq is used to identify trait-linked single-nucleotide polymor- phisms in NLRs in a potato population that was segregating for disease resistance.

However, extensive sequence diversity among parental $\mathrm{R}$ gene families prevents the identification of the individual $\mathrm{R}$ genes responsible for resistance (Steuernagel et al., 2016). The prospects for using dominant major Rpi genes for disease control have been greatly improved by recent advances. Previously, breeders were unable to prioritize Rpi genes that recognized the pathogen's most indispensable effectors; now they can. Moreover, if one can combine multiple Rpi genes on one DNA construct ('stacking'), then each gene can be expected to reduce the selection pressure against the other genes on the construct (Zhu et al., 2012). BASF developed a potato variety, Fortuna, which carries Rpi-blb1 and Rpi-blb2, and showed excellent field resistance (Jones et al., 2014).

\subsubsection{Viral Diseases}

Plant viruses significantly reduce yields in all cultivated crops. Engineered cross protection is one way of controlling viral diseases (Mundembe et al., 2012). Some of the important viral pathogens of rice are Tungro viruses, Rice Stripe Virus, Rice Hoja Blanca Virus and Rice Yellow Mottle virus. Proteinmediated and RNA-mediated resistance are the two strategies used to develop successful transgenic viral resistance in rice (Sanford and Johnston, 1985). Both of the strategies depend on the concept of 'pathogen-derived resistance (Dutta et al., 2016). Small RNA based genetic engineering has been applied in engineering viral resistance for many crops, including major crops of staple food, vegetables, fruits ornamentals, and some cash crop (Khalid, et al., 2017).

According to the International Service for the Acquisition of Agri Biotech Applications (ISAAA) website, dozens of transgenic crops resistance to virus generated with SRGE were approved for commercial release. Potato and the United States ranks the top among different crops and countries, respectively in terms of number of lines approved (Khalid, et al. 2017). Banana aphid-transmitted Banana bunchy top virus (BBTV)-resistant transgenic banana was developed with hp-PTGS mechanism targeting Rep gene (Shekhawat et al., 2012; Elayabalan et al., 2013). Citrus tristeza virus (CTV)-resistant citrus was obtained with hp-PTGS targeting multiple VSR genes in the virus genome (Soler et al., 2012) while targeting single VSR is not effective plum pox virus (PPV)-resistant plum was also obtained with hairpin post- transcriptional gene silencing (hp-PTGS) mechanism targeting CP gene (Ravelonandro et al., 2014). PVX-resistant potato, CMV-resistant tomato and pepper with dual resistance to ToMV and cucumber mosaic virus were obtained by means of sense gene induced post- transcriptional gene silencing (S-PTGS). Since then potato leaf role virus, PVX, and PVYimmune potato was developed with hp-PTGS mechanism targeting PLRV-CP, PVX- CP, and PVY- 
HcPro simultaneously (Arif et al., 2012). Currently, about 14 transgenic potato lines approved for commercial release in US and other countries and all are developed by the Monsanto Company. One pepper and one tomato line were developed by Peking University and approved for commercial release in China (Khalid et al., 2017).

Transgenic maize resistant to maize dwarf mosaic virus (MDMV) was generated with hp-PTGS mechanism targetingPlandCP (Zhang et al., 2013). Transgenic wheat resistant to Wheat streak mosaic virus was created with all three generations of SRGE and newer ones appeared to provide better protection (Fahim et al., 2012). The most important viral threat for rice production came from Phytoreoviruses, Tenuiviruses, Tungroviruses, and Waikavirus, such as rice yellow mottle viruses, Rice Stripe Virus, rice tungro bacilliform (RTBV), and rice tungro spherical (RTSV). These viral pathogens caused significant losses in rice production in Asia and many resistant transgenic rice lines were generated using hp-PTGS mechanism (Sasaya et al., 2014). Some of the resistance traits had been introgressed into cultivated rice varieties (Valarmathi et al., 2016).

All these commercially released crops were developed based on the first generation Small RNA based genetic engineering (SRGE) technology. Papaya provided the first successful example for tackling down the virus threats in agriculture with the SRGE. Overcoming of resistance by more virulent PRSV strain was observed and new resistant transgenic papaya was obtained by targeting the viral HcPro protein that suppresses small RNA mediated immunity (Kung et al., 2015). Currently, there are four commercial transgenic papaya lines approved with three in USA and one in China (Khalid et al., 2017).

\subsubsection{Fungal Disease}

Fungal pathogens pose a major challenge to global crop production. Pathogenic microbes are responsible for severe production losses in crops worldwide. The use of disease resistant crop varieties can be a sustainable approach to meet the food demand of the world's growing population. However, classical plant breeding is usually laborious and time-consuming, thus hampering efficient improvement of many crops. With the advent of genome editing technologies, in particular the CRISPR-Cas9 (clustered regularly interspaced short palindromic repeats-Cas9) system, it is possible to improve crop traits in a rapid and efficient manner. Recently, it was demonstrated that inactivation of a single gene called DMR6 (downy mildew resistance 6) confers resistance to several pathogens in Arabidopsis thaliana. The tomato SIDMR6-1 orthologue Solyc03g080190 is also up-regulated during infection by Pseudomonas syringae PV. Tomato and Phytophthora capsici, using the CRISPR-Cas9 system, can generate tomato plants with small deletions in the SIDMR6-1 gene that result in frame shift and premature truncation of the protein (de Toledo et al., 2016).

The transfer of certain Arabidopsis immunity genes provides resistance to Asian soybean rust disease in soybean plants in the greenhouse (Langenbach et al., 2016). The development of genetic resistance by incorporating new genes through genetic engineering is an attractive way to combat the pathogen 'Phytophthora infestans' causing late blight disease of potato. The development of transgenic potato cultivars over expressing the rice oxalate oxidase 4 genes (Osoxo4) was developed (Ghosh et al., 2016). Detached leaf bioassays with spore suspension and in vitro plantlet bioassays with mycelia of $P$. infestans showed enhanced resistance in transgenic plants. Interestingly, constitutive over expression of Osoxo4 did not show any effect on the morphology and yield of transgenic potato plants as evident from agronomic performance studies. The constitutive expression of Osoxo4 represents an efficient strategy for engineering late blight resistance in potato (Ghosh et al., 2016). Traditional breeding programmes have not been able to achieve long standing resistance, mainly because of the remarkable capacity of $\mathrm{P}$. infestans to adapt rapidly to resistant plants (Haverkort et al., 2008). The genes Rpi-blb2 and RB cloned from the wild potato Solanum bulbocastanum have been demonstrated to provide resistance against Phytophthora infestans when expressed in cultivated potato (Solanum tuberosum) (Orbegozo et al., 2016).

The study illustrate that with an account of a genetically modified (GM) blight-resistant potato trial in Norwich, using the Rpi-vnt1, gene isolated from a wild relative of potato, Solanum venturii, and introduced by GM methods into the potato variety known as' Desiree' (Jones et al., 2014). The potato (Solanum tuberosum) can be crossed with a number of wild Solanum species; however, certain genetic restrictions can be applied. For example, the same ploidy level and genetic background must usually be present to generate viable crosses (Jones et al., 2014). RenSeq can be used to isolate two wheat stem rust resistance genes, $\mathrm{Sr} 22$ and $\mathrm{Sr} 45$, which mediate resistance to the stem rust pathogen 
Puccinia graminis f.sp tritici (Steuernagel et al., 2016). MutRenSeq will enable the rapid isolation of functional $\mathrm{R}$ genes from plant species amenable to mutational genomics and is particularly applicable to organisms with large genomes for which whole genome sequencing of multiple individuals is neither straightforward nor cost-effective (Henry et al., 2014). In wheat cultivar Schomburgk, Sr22 confers resistance to commercially important races of the stem rust pathogen, including the Ug99 race group, which threatens wheat production in Africa. Sr22 is one of the few R genes that are effective against Yemeni and Ethiopian stem- rust isolates (Olivera Firpo et al., 2015).

\subsubsection{Bacterial Disease}

The findings indicate that the biological function of AtDMR6homologues might be conserved among different plant species. In particular, resistance to Xanthomonas spp. is highly desired. X. gardneri and $\mathrm{X}$. perforans belong to a complex of four Xanthomonas species (X. euvesicatoria, X. vesicatoria, X. perforans and $X$. gardneri) that incite bacterial spot disease in tomato. Bacterial spot disease is one of the most devastating and widespread diseases of this crop that can cause significant losses when environmental conditions are suitable for the pathogen (i.e. moderate-to-high temperatures and high humidity) (Schwartz et al., 2015). The use of chemicals for controlling bacterial spot disease have not been effective due to the emergence of tolerant strains and the significant negative impact on the environment (Abbasi et al., 2015). For this reason, resistance against bacterial spot has been a priority in tomato breeding programs. The $\mathrm{R}$ protein Bs2 has been identified in pepper, and is able to recognize a highly conserved Xanthomonas effector named AvrBs2, thus triggering HR. The evidence shows that trials have shown that transgenic tomato plants expressing the Bs2 gene show high disease resistance and significant increased yield (Horvath et al., 2012) Although very promising, resistance based on the deployment of a single $\mathrm{R}$ gene can be rapidly overcome by the pathogen due to the emergence of resistant strains (Dangl et al., 2013). Moreover, Bs2 specifically recognizes a single effector in a specific species, limiting the use of these resistant tomato lines. In this regard, to engineer long-lasting and broad-spectrum disease resistance in tomato, the combination of Bs2 deployment with DMR6 inactivation is a very promising approach. In rice, more than 70 diseases have been recorded; caused by fungi, bacteria, viruses or nematodes (Zhang et al., 2009). Though resistant cultivars and application of chemical pesticides have been widely used, using the techniques of genetic engineering to develop transgenic rice resistant to diseases is more significant to durable resistance, giving protection for a long time and over a broad geographic area.

\section{INSECT-RESISTANT CROPS THROUGH GENETIC ENGINEERING}

Insect-borne pathogens impose a substantial burden on health, the environment, and agricultural production, and rapid outbreaks of such pathogens are becoming more common (Gatherer et al., 2015). Population control is an important component of strategies to control insect-borne pathogens. An emerging technology that could form part of strategies for controlling insect-borne pathogens is to suppress or replace insect populations by releasing genetically modified (GM) insects. Trial releases of GM insects for disease control have now been conducted in Brazil (Carvalho et al., 2015). In 2015, the only active European GM insect application (olive fly) was withdrawn two years after submission in response to the cost of additional experiments requested by the regulators (Oxitec, 2016). Regardless of the method of crop genetic improvement, there is considerable potential to increase protection of crops from insect attack by planting insect resistant seeds (Tamiru et al., 2015). The current study shows that rice tps46 (Os08g0167800) is a key gene responsible for biosynthesis of limonene, methyl salicylate, Ebf, $(E)$-b-caryophyllene, a-bisabolene, $(E)$ - a-bergamotene, and ahumulene from FPP. Among these volatiles, constitutive emissions of limonene and Ebf may due to the constitutive expressions of tps 46 under natural conditions in rice. Furthermore, it is shown that silencing expression of tps 46 makes rice vulnerable to attack by an herbivore, R.padi, which does not usually attack wild type rice. This finding suggests that TPS46 plays an important role in rice innate immunity to aphids (Sun et al., 2017). The commercialization of insect-resistant crops expressing Bt genes has been outstanding in terms of crop productivity and economic benefits to the farming community. However, it is important to note here that almost all commercialized insect-resistant crops contain genes from Bacillus thuringiensis (Bakhsh et al., 2015).

Despite continuous plant breeding efforts, chemical control is the preferred management method for insect pests. New genetic methods for insect control could substantially reduce expenditures, crop losses and be less detrimental to the environment. A very successful molecular approach to engineering resistance has involved generating plants with the capability of synthesizing antimicrobial or insecticidal products. These products are usually constitutively produced in plants. In certain cases, 
an inducer is necessary for gene expression in order to activate synthesis of these engineered chemicals once the presence of a pest is detected. For example, the tetra cyc line inducible promoter system is the best characterized system. Since large quantities of tetracycline may be needed for induction, this system is not be ideal. Therefore, alternative inducers are currently being developed.

\subsection{Bt Technology}

Bt technology is an example of genetic engineering used to develop insect resistant crops now and in the future. Bt is very selective - different strains of the bacterium kill different insects and only those insects. Strains of Bt are effective against European corn borers and cotton bollworms (Lepidoptera), Colorado potato beetles (Coleoptera), and certain flies and mosquitos (Diptera). Today, plants can be genetically engineered to produce their own Bt. The hereditary information is contained in individual units or sections of DNA called genes. The genes that are passed from parent to offspring determine the traits that the offspring will have. DNA technology makes it possible to locate the gene that produces Bt proteins lethal to insects and transfer the gene into crop plants. Scientists identify a strain of $\mathrm{Bt}$ that kills the targeted insect. Then they isolate the gene that produces the lethal protein. That gene is removed from the Bt bacterium and a gene conferring resistance to a chemical (usually antibiotic or herbicide) is attached that will prove useful in a later step. The Bt gene with the resistance gene attached is inserted into plant cells. At this point, scientists must determine which plant cells have successfully received the Bt gene and are now transformed. Any plant cell that has the Bt gene must also have the resistance gene that was attached to it. These genetically transformed plant cells are then grown into whole plants by a process called tissue culture. The modified plants produce the same lethal Bt protein produced by Bt bacteria because the plants now have the same gene.

A finding shows that Bt cotton can be genetically modified with genes from Bacillus thuringiensis (Bt) to make the plant resistant to the bollworm, a major insect pest in cotton production. As one of the first genetically modified (GM) crops, Bt cotton was commercialized in the United States in 1996. Since then, this technology has been approved and widely adopted in several other cotton-growing countries. In 2012, GM cotton was grown on 60 million acres worldwide (James, 2012). In Pakistan the first Bt technology is officially approved only in 2010. Unlike other countries, where Bt cotton is commercialized by the US Company Monsanto, Bt varieties are developed by different public and private sector organizations. In 2012, 6.9 million acres were grown with Bt a variety which is equivalent to 82 per cent of the country's total cotton area (James, 2010).

Bt cotton technologies are advantages in terms of reduced incidence of acute pesticide poisoning, and environmental advantages in terms of higher biodiversity and lower soil and groundwater contamination (Kouser and Qaim, 2013). Cotton yields are significantly higher on Bt than on non-Bt plots; the observed yield difference is $28 \%$. This difference is not due to higher genetic yield potentials of $\mathrm{Bt}$ varieties, but due to reduced crop losses. In spite of chemical pesticide applications, bollworms cause sizeable yield damage in conventional cotton, which can be controlled more effectively with Bt technology. Bt cotton has been genetically modified (GM) through insertion of genes from Bacillus thuringiensis $(\mathrm{Bt})$ to make the plant resistant to cotton bollworms. Bollworms are a group of insect pest species, which cause significant crop damage and are responsible for heavy chemical pesticide applications in almost all of the world's cotton growing regions (Zehr, 2010) over the last 15 years, Bt cotton has been adopted widely in a number of countries. Studies show that this technology contributes to lower pesticide use, reduced crop damage, and higher farm incomes (Carpenter, 2010).

\section{WEED-RESISTANT CROPS THROUGH GENETIC ENGINEERING}

It is known that in nature there is a genetic flow among plants of the same species and among plants of related species. There is a body of scientific evidence that genetic material introduced into certain species of crops will recombine with related weed species (Dale et al., 2002). Herbicide resistance allows a crop to survive the application of a herbicide which would otherwise kill it. Most herbicideresistant GE crops are engineered to be resistant to glyphosate, commonly known as RoundUp. Studies indicate that herbicide-resistant crops contribute to greater yield where weed control is improved because of the specific herbicides that can be used in conjunction with the herbicideresistant crop (NASEM, 2017). In locations where glyphosate is used extensively, weed species that are naturally less susceptible to that herbicide may populate a field. In many locations, some weeds have evolved resistance to glyphosate. Integrated weed-management approaches can be used to delay resistance, especially in cropping systems not yet exposed to continuous glyphosate applications. 
In 2015, almost 180 million hectares of GE crops were planted globally, which was about 12 percent of the world's planted cropland that year (NASEM, 2017). There were herbicide-resistant varieties of maize, soybean, cotton, canola, sugar beet, and alfalfa, and insect-resistant varieties of maize, cotton, poplar, and eggplant. Research is needed to improve strategies for management of resistance in weeds (NASEM, 2017). The comparisons with conventional breeding indicate, comparing GE to nonGE crop yields and also examined changes over time in overall yield per hectare of maize, soybean, and cotton reported by the U.S. Department of Agriculture (USDA) before, during, and after the switch from conventionally bred to GE varieties of these crops. Although the sum of experimental evidence indicates that GE herbicide resistance and insect resistance are contributing to actual yield increases, there is no evidence from USDA data that the average historical rate of increase in U.S. yields of cotton, maize, and soybean has changed (NASEM, 2017).

\section{SUMMARY AND CONCLUSION}

The principles of genetic engineering can be utilized to express non-native genes within the host organism, leading to the expression of previously unavailable protein products. The genetic engineering approach to cross protection was first demonstrated by Powell-Abel and co-workers who expressed the TMV coat protein gene in transgenic plants and obtained some degree of resistance against TMV. Biotechnology is the use of genetic engineering techniques to manipulate microorganisms, plants, and animals in order to produce commercial products and processes that benefit man.

BASF developed a potato variety, Fortuna, which carries Rpi-blb1 and Rpi-blb2, and showed excellent field resistance Small RNA based genetic engineering has been applied in engineering viral resistance for many crops, including major crops of staple food, vegetables, fruits ornamentals, and some cash crop. Engineered cross protection is one way of controlling viral (Rice Stripe Virus, Rice Hoja Blanca Virus and Rice Yellow Mottle virus, BBTV, CTV PPT, etc), fungal (rust, down mildew, blight etc), bacterial (Xanthomonas species, bacterial spot disease) diseases and etc. An emerging technology that could form part of strategies for controlling insect-borne pathogens that used to suppress or replace insect populations by releasing genetically modified (GM) insects Bt technology through the use of genetic engineering. It is important to note here that almost all commercialized insect-resistant crops contain genes from Bacillus thuringiensis.

Bt varieties are developed by different public and private sector organizations. Bt cotton technologies are advantages in terms of reduced incidence of acute pesticide poisoning, and environmental advantages in terms of higher biodiversity and lower soil and groundwater contamination. Cotton yields are significantly higher on Bt than on non-Bt plots; the observed yield difference is $28 \%$. This difference is not due to higher genetic yield potentials of Bt varieties, but due to reduced crop losses. In spite of chemical pesticide applications, bollworms cause sizeable yield damage in conventional cotton, which can be controlled more effectively with Bt technology. Generally, through the use of genetic engineering it is possible to develop resistant variety for biotic factors such as disease, insect pest and invasive weeds for any crop plants.

\section{REFERENCES}

Abbasi, P.A., Khabbaz, S.E., Weselowski, B. and Zhang, L., 2015. Occurrence of copper-resistant strains and a shift in Xanthomonas spp. causing tomato bacterial spot in Ontario. Canadian journal of microbiology, 61(10), pp.753-761.

Andolfo, G., Jupe, F., Witek, K., Etherington, G.J., Ercolano, M.R. and Jones, J.D., 2014. Defining the full tomato NB-LRR resistance gene repertoire using genomic and cDNA RenSeq. BMC plant biology, 14(1), p. 120 .

Arif, M., Azhar, U., Arshad, M., Zafar, Y., Mansoor, S. and Asad, S., 2012. Engineering broad-spectrum resistance against RNA viruses in potato. Transgenic research, 21(2), pp.303-311.

Ascacio-Martínez, J.A. and Barrera-Saldaña, H.A., 2012. Genetic engineering and biotechnology of growth hormones. INTECH Open Access Publisher.

Bakhsh, A., Khabbazi, S.D., Baloch, F.S., Demirel, U., ÇALIŞKAN, M.E., HATİPOĞLU, R., ÖZCAN, S. and ÖZKAN, H., 2015. Insect-resistant transgenic crops: retrospect and challenges. Turkish Journal of Agriculture and Forestry, 39(4), pp.531-548.

Carpenter, J.E., 2010. Peer-reviewed surveys indicate positive impact of commercialized GM crops. Nature biotechnology, 28(4), pp.319-321.

Carvalho, D.O., McKemey, A.R., Garziera, L., Lacroix, R., Donnelly, C.A., Alphey, L., Malavasi, A. and Capurro, M.L., 2015. Suppression of a field population of Aedes aegypti in Brazil by sustained release of transgenic male mosquitoes. PLoS Negl Trop Dis, 9(7), p.e0003864. 
Close, D., Xu, T., Smartt, A., Price, S., Ripp, S. and Sayler, G., 2012. Expression of Non-native genes in a surrogate host organism. In Genetic Engineering-Basics, New Applications and Responsibilities. InTech.

Dangl, J.L., Horvath, D.M. and Staskawicz, B.J., 2013. Pivoting the plant immune system from dissection to deployment. Science, 341(6147), pp.746-751.

de Toledo Thomazella, D.P., Brail, Q., Dahlbeck, D. and Staskawicz, B.J., 2016. CRISPR-Cas9 mediated mutagenesis of a DMR6 ortholog in tomato confers broad-spectrum disease resistance. bioRxiv, p.064824.

Dutta, S.S., Pale, G., Iangrai, B., Aochen, C., Rai, M. and Pattanayak, A., 2016. Current status and future prospects of research on genetically modified rice: A review. Agricultural Reviews, 37(1), pp.10-18.

Fahim, M., Millar, A.A., Wood, C.C. and Larkin, P.J., 2012. Resistance to Wheat streak mosaic virus generated by expression of artificial polycistronic microRNA in wheat. Plant biotechnology journal, 10(2), pp.150163.

Freeman, S. and Mwang'ombe, A.W., 2009. CROP PROTECTION THROUGH PEST-RESISTANT GENES. BIOTECHNOLOGY-Volume VIII: Fundamentals in Biotechnology, p.81.

Gatherer, D. and Kohl, A., 2016. Zika virus: a previously slow pandemic spreads rapidly through the Americas. Journal of General Virology, 97(2), pp.269-273.

Ghosh, S., Molla, K.A., Karmakar, S., Datta, S.K. and Datta, K., 2016. Enhanced resistance to late blight pathogen conferred by expression of rice oxalate oxidase 4 gene in transgenic potato. Plant Cell, Tissue and Organ Culture (PCTOC), 126(3), pp.429-437.

Henry, I.M., Nagalakshmi, U., Lieberman, M.C., Ngo, K.J., Krasileva, K.V., Vasquez-Gross, H., Akhunova, A., Akhunov, E., Dubcovsky, J., Tai, T.H. and Comai, L., 2014. Efficient genome-wide detection and cataloging of EMS-induced mutations using exome capture and next-generation sequencing. The Plant Cell, 26(4), pp.1382-1397.

Horvath, D.M., Stall, R.E., Jones, J.B., Pauly, M.H., Vallad, G.E., Dahlbeck, D., Staskawicz, B.J. and Scott, J.W., 2012. Transgenic resistance confers effective field level control of bacterial spot disease in tomato. PLoS One, 7(8), p.e42036.

James, C., 2010. Global status of commercialized Biotech/GM crops: 2010. ISAAA briefs, (42).

Jones, J.D., Witek, K., Verweij, W., Jupe, F., Cooke, D., Dorling, S., Tomlinson, L., Smoker, M., Perkins, S. and Foster, S., 2014. Elevating crop disease resistance with cloned genes. Philosophical Transactions of the Royal Society B: Biological Sciences, 369(1639), p.20130087.

Jupe, F., Witek, K., Verweij, W., Śliwka, J., Pritchard, L., Etherington, G.J., Maclean, D., Cock, P.J., Leggett, R.M., Bryan, G.J. and Cardle, L., 2013. Resistance gene enrichment sequencing (RenSeq) enables reannotation of the NB-LRR gene family from sequenced plant genomes and rapid mapping of resistance loci in segregating populations. The Plant Journal, 76(3), pp.530-544.

Khalid, A., Zhang, Q., Yasir, M. and Li, F., 2017. Small RNA based genetic engineering for plant viral resistance: application in crop protection. Frontiers in Microbiology, 8.

Kouser, S. and Qaim, M., 2013. Valuing financial, health, and environmental benefits of Bt cotton in Pakistan. Agricultural Economics, 44(3), pp.323-335.

Kung, Y.J., You, B.J., Raja, J.A., Chen, K.C., Huang, C.H., Bau, H.J., Yang, C.F., Huang, C.H., Chang, C.P. and Yeh, S.D., 2015. Nucleotide sequence-homology-independent breakdown of transgenic resistance by more virulent virus strains and a potential solution. Scientific reports, 5, p.9804.

Langenbach, C., Schultheiss, H., Rosendahl, M., Tresch, N., Conrath, U. and Goellner, K., 2016. Interspecies gene transfer provides soybean resistance to a fungal pathogen. Plant biotechnology journal, 14(2), pp.699708.

Mundembe, R., Allison, R.F. and Sithole-Niang, I., 2012. Genetic Engineering of Plants for Resistance to Viruses. In Genetic Engineering-Basics, New Applications and Responsibilities. InTech.

National Academies of Sciences, Engineering, and Medicine, 2017. Genetically Engineered Crops: Experiences and Prospects. National Academies Press.

Olivera, P., Newcomb, M., Szabo, L.J., Rouse, M., Johnson, J., Gale, S., Luster, D.G., Hodson, D., Cox, J.A., Burgin, L. and Hort, M., 2015. Phenotypic and genotypic characterization of race TKTTF of Puccinia graminis f. sp. tritici that caused a wheat stem rust epidemic in southern Ethiopia in 2013-14. Phytopathology, 105(7), pp.917-928.

Orbegozo, J., Roman, M.L., Rivera, C., Gamboa, S., Tovar, J.C., Forbes, G.A., Lindqvist-Kreuze, H., Kreuze, J.F. and Ghislain, M., 2016. Rpi-blb2 gene from Solanum bulbocastanum confers extreme resistance to late blight disease in potato. Plant Cell, Tissue and Organ Culture (PCTOC), 125(2), pp.269-281.

Powell-Abel, P., Nelson, R.S., De B., Hoffmann, N., Rodger, S.G., Fraley, R.T. and Beachy, R.N. 1986. Delay of disease development in transgenic plants that express the tobacco mosaic virus coat protein gene. Science, 232: 738 - 743 . 
Ravelonandro, M., Scorza, R., Michel, H.J. and Briard, P., 2014. The efficiency of RNA interference for conferring stable resistance to Plum pox virus. Plant Cell, Tissue and Organ Culture (PCTOC), 118(2), pp.347-356.

Sasaya, T., Nakazono-Nagaoka, E., Saika, H., Aoki, H., Hiraguri, A., Netsu, O., Uehara-Ichiki, T., Onuki, M., Toki, S., Saito, K. and Yatou, O., 2014. Transgenic strategies to confer resistance against viruses in rice plants.

Saurabh, S., Vidyarthi, A.S. and Prasad, D., 2014. RNA interference: concept to reality in crop improvement. Planta, 239(3), pp.543-564.

Schwartz, A.R., Potnis, N., Timilsina, S., Wilson, M., Patané, J., Martins, J., Minsavage, G.V., Dahlbeck, D., Akhunova, A., Almeida, N. and Vallad, G.E., 2015. Phylogenomics of Xanthomonas field strains infecting pepper and tomato reveals diversity in effector repertoires and identifies determinants of host specificity. Frontiers in microbiology, 6, p.535.

Shekhawat, U.K., Ganapathi, T.R. and Hadapad, A.B., 2012. Transgenic banana plants expressing small interfering RNAs targeted against viral replication initiation gene display high-level resistance to banana bunchy top virus infection. Journal of general virology, 93(8), pp.1804-1813.

Small, B., 2012. Genetic Engineering and Moral Responsibility. In Genetic Engineering-Basics, New Applications and Responsibilities. InTech.

Soler, N., Plomer, M., Fagoaga, C., Moreno, P., Navarro, L., Flores, R. and Peña, L., 2012. Transformation of Mexican lime with an intron-hairpin construct expressing untranslatable versions of the genes coding for the three silencing suppressors of Citrus tristeza virus confers complete resistance to the virus. Plant biotechnology journal, 10(5), pp.597-608.

Sun, Y., Huang, X., Ning, Y., Jing, W., Bruce, T.J., Qi, F., Xu, Q., Wu, K., Zhang, Y. and Guo, Y., 2017. TPS46, a rice terpene synthase conferring natural resistance to bird cherry-oat aphid, Rhopalosiphum padi (Linnaeus). Frontiers in Plant Science, 8

Tamiru, A., Khan, Z.R. and Bruce, T.J., 2015. New directions for improving crop resistance to insects by breeding for egg induced defence. Current Opinion in Insect Science, 9, pp.51-55.

Tanaka, Y., Kimura, T., Hikino, K., Goto, S., Nishimura, M., Mano, S. and Nakagawa, T., 2012. Gateway vectors for plant genetic engineering: Overview of plant vectors, application for bimolecular fluorescence complementation (BiFC) and multigene construction. In Genetic Engineering-Basics, New Applications and Responsibilities. InTech.

Valarmathi, P., Kumar, G., Robin, S., Manonmani, S., Dasgupta, I. and Rabindran, R., 2016. Evaluation of virus resistance and agronomic performance of rice cultivar ASD 16 after transfer of transgene against Rice tungro bacilliform virus. Virus genes, 52(4), pp.521-529.

Yuan, D., Bassie, L., Sabalza, M., Miralpeix, B., Dashevskaya, S., Farre, G., Rivera, S.M., Banakar, R., Bai, C., Sanahuja, G. and Arjó, G., 2011. The potential impact of plant biotechnology on the Millennium Development Goals. Plant cell reports, 30(3), pp.249-265.

Zhang, Z.Y., Wang, Y.G., Shen, X.J., Li, L., Zhou, S.F., Li, W.C. and Fu, F.L., 2013. RNA interferencemediated resistance to maize dwarf mosaic virus. Plant Cell, Tissue and Organ Culture (PCTOC), 113(3), pp.571-578.

Zehr, U.B., Ed. (2010). 'Cotton: Biotechnological Advances', Heidelberg: Springer.

Zhu, S., Li, Y., Vossen, J.H., Visser, R.G. and Jacobsen, E., 2012. Functional stacking of three resistance genes against Phytophthora infestans in potato. Transgenic research, 21(1), pp.89-99.

Citation: D. Alemayehu, "Application of Genetic Engineering in Plant Breeding for Biotic Stress Resistance", International Journal of Research Studies in Biosciences (IJRSB), vol. 5, no. 9, pp. 28-35, 2017. http://dx. doi.org/10.20431/2349-0365.0509006

Copyright: (c) 2017 Authors. This is an open-access article distributed under the terms of the Creative Commons Attribution License, which permits unrestricted use, distribution, and reproduction in any medium, provided the original author and source are credited. 